\title{
PENGARUH PELAYANAN KUNJUNGAN PASTORAL TERHADAP PERTUMBUHAN ROHANI JEMAAT
}

\author{
Mikha Agus Widiyanto ${ }^{1}$ \& Susanto $^{2}$ \\ ${ }^{1}$ Sekolah Tinggi Teologi Tenggarong, ${ }^{2}$ Sekolah Tinggi Teologi Simpson \\ ${ }^{1}$ Jl. Stadion Rt. 12, Tenggarong, Kutai Kartanegara, Kalimantan Timur, Indonesia \\ ${ }^{2}$ Jl. Agung No. 66, Susukan, Ungaran Timur, Kab. Semarang, Jawa Tengah, Indonesia \\ Email: ${ }^{1}$ mikha.agus08@gmail.com, ${ }^{2}$ susanto_rosa@yahoo.com
}

\begin{abstract}
This research aim to test the influence of pastoral visiting ministry to the spiritual growth of the church. Research executed in Gereja Kemah Injil Indonesia of Tenggarong, Kutai Kartanegara District, Kalimantan East. The results showed that there was an influence of pastoral visiting ministry on the spiritual growth of the congregation as indicated by the correlation coefficient of 0.340 which was significant at $\alpha=0.05$. Pastoral visiting ministry will bring the pastor closer to the congregation the serves, making the pastoral ministry effective, thereby impacting the spiritual growth of the congregation.
\end{abstract}

Keywoard :Ministry, Pastoral Visits, Spiritual Growth

\begin{abstract}
ABSTRAK: Penelitian ini bertujuan untuk menguji pengaruh pelayanan kunjungan pastoral terhadap pertumbuhan rohani jemaat.Penelitian dilaksanakan di Gereja Kemah Injil Indonesia Tenggarong, Kabupaten Kutai Kartanegara, Kalimantan Timur. Hasil penelitian diperoleh bahwa terdapat pengaruh pelayanan kunjungan pastoral terhadap pertumbuhan rohani jemaat yang ditunjukkan melalui koefisien korelasi sebesar 0,340 yang signifikan pada $\alpha=0,05$. Pelayanan kunjungan pastoral akan mendekatkan gembala dengan jemaat yang dilayaninya, membuat pelayanan penggembalaan menjadi efektif, sehingga berdampak pada pertumbuhan rohani jemaat.
\end{abstract}

Kata Kunci: Pelayanan, Kunjungan Pastoral, Pertumbuhan Rohani

\section{PENDAHULUAN}

Gembala sebagai pemimpin gereja memiliki tanggungjawab untuk mewujudkan kedewasaan rohani jemaat. Upaya dalam mewujudkan, tidak dapat dilakukan hanya fokus pada pelayanan khotbah dalam ibadah saja, melainkan perlu hubungan kedekatan yang dapat dilakukan dengan melakukan kunjungan pastoral. Clinebell (2006, p. 96) menyatakan bahwa pelayanan kunjungan pastoral dapat memperkuat kehangatan pelayanan pendeta selama kebaktian di gereja. Hubungan pendampingan dilanjutkan dan diperkuat lagi dengan perhatian yang diberikan pendeta melalui kunjungan. Kunjungan pastoral menjadi kekuatan bagi gembala dalam pelayanan penggembalaan dalam upaya menjaga dan memelihara jemaat (Riemer, 2005, p. 9). Kunjungan sangat membantu gembala dalam mengenal jemaat, secara khusus bagi gembala yang baru di wilayah pelayanannya tersebut. Melalui kunjungan inilah gem- bala mencari tahu kebutuhan jemaat dalam hidup rohani, harapannya atas pelayanan gereja, sehingga gembala dapat membuat tujuan dan rencana yang relevan dengan kebutuhan tersebut (Cowles, 1977, p. 13; Kosta \& Djadi, 2011; Pranoto et al., 2018).

Sedangkan menurut Mimery (1996, p. 53) bahwa pelayanan kunjungan merupakan suatu kegiatan resmi gereja yang sangat penting dalam membina hubungan yang erat dengan jemaat-jemaatnya. Hubungan antara kedua pihak inilah yang membuat gembala jemaat atau pengurus gereja dapat mengetahui keadaan yang sedang dialami oleh jemaat-jemaatnya, sehingga gereja dapat melayaninya secara efektif. Pelayanan penggembalaan akan menjadi efektif ketika gembala dapat mengenal dan mengetahui kebutuhan jemaat, sehingga mampu mendisain pelayanan penggembalaan secara tepat dan relevan. Pelayanan demikian akan meningkatkan kepuasan jemaat atas layanan gereja dan mendorong serta me- 
ningkatkan loyalitas jemaat kepada gereja (Panjaitan \& Siahaan, 2017).

Kata melawat dalam Matius 25:36 merupakan terjemahan dari kata dalam bahasa Yunani, yaitu

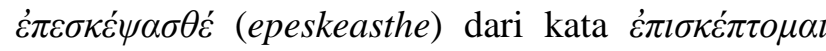
(episkeptomai), yang berarti to look upon or after, to inspect, examine with the eyes (Bibleworks, n.d.). Kata episkeptomai ini digunakan pada kegiatan kunjungan yang dilakukan kepada orang sakit, dimana kunjungan yang dilakukan dalam upaya untuk membantu dan menjaga (Ingouf, 1988, p. 57). Kisah Para Rasul 15:36, Alkitab Bahasa Indonesia Terjemahan Baru tertulis “... baiklah kita kembali kepada saudara-saudara kita di setiap kota, di mana kita telah memberitakan firman Tuhan, untuk melihat, bagaimana keadaan mereka,". Sedangkan dalam King James Version (KJV) tertulis bahwa "Let us go again and visit our brethren in every city where we have prea-ched the word of the Lord, and see how they do." Kata melihat sebenarnya terjemahan dari

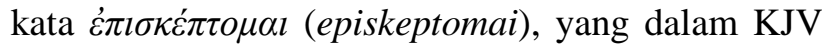
menerjemahkan dengan kata visit yang berarti mengunjungi. Kata episkeptomai digunakan untuk menunjuk pada kunjungan yang dilakukan kepada seseorang untuk melihat keadaan orang menderita, miskin, sakit atau membutuhkan perawatan guna memberikan bantuan atau sebagai wujud kepedulian.

Menurut Ingouf (1988, p. 57) bahwa penggunaan kata episkeptomai, menjelaskan bahwa kata ini mempunyai arti sebagai berikut: 1) memeriksa dengan maksud menambah pengertian dan pengenalan. Kunjungan adalah salah satu cara yang penting untuk seorang gembala agar dapat lebih mengerti dan mengenal anggota gerejanya; 2) Meninjau dengan maksud menolong dan melayani. Antara lain kita harus siap sedia melayani dengan Firman, doa, perhatian dan lain sebagainya; 3) Melibatkan diri dalam hubungan dengan orang lain. Memang tiap orang Kristen bertanggung jawab mengunjungi orang yang seiman dan sesama manusia pada umumnya. Gembala juga harus pergi mengunjungi seseorang di rumahnya.
Menurut Clinebell (2006, pp. 95-97), dan Beek (1992, p. 3), bahwa fungsi dan tujuan pelayanan kunjungan adalah 1) menyembuhkan, 2) menopang, 3) membimbing, 4) mengasuh atau memelihara, 5) membantu kelahiran dan pertumbuhan, dan 6) pemulihan atau memperbaiki hubungan. Melalui pelaksanaannya, dimana fungsi dan tujuan dari pelayanan kunjungan diwujudkan, maka akan berdampak pada peningkatan pertumbuhan gereja, baik secara kualitatif maupun kuantitatif. Pelayanan kunjungan sebagai salah satu wujud pelayanan pastoral yang berdampak pada pertumbuhan gereja. Gereja yang menghentikan pelayanan kunjungan, maka gereja tersebut menghentikan suatu pelayanan yang sangat penting yang seharusnya justru dipertahankannya (Cedar et al., 1991, p. 18). Dalam Yohanes 10 diceritakan gembala yang baik adalah yang mengenal domba-dombanya dan domba-dombanya mengenal serta mendengarkan suaranya. Ia menuntun, menjaga dan membela domba-dombanya terhadap serangan binatang buas. Melalui pelayanan kunjungan inilah jemaat dituntun, dibimbing dan ditopang sehingga secara kualitas akan meningkatkan kehidupan rohani yang kemudian akan berdampak pada aspek kuantitas gereja. Jemaat yang berkualitas dirinya akan melakukan amanat agung Tuhan Yesus, yang pada akhirnya akan berdampak pada peningkatan jumlah anggota jemaat. Sejalan dengan pernyataan Wongso (2001, p. 69) bahwa dasar dari gereja yang bertumbuh secara kualitas adalah kedewasaan kerohanian jemaat secara pribadi. Apabila jemaat memiliki kedewasaan rohani, maka dengan sendirinya akan berdampak pada penambahan jumlah orang percaya. Kosta dan Djadi (2011, p. 175) menyatakan bahwa gembala sebagai pemimpin, dalam pelaksanaan tugas penggembalaan berperan dalam menentukan pertumbuhan gereja.

Wongso (2001, p. 69) lebih lanjut menyatakan bahwa pertumbuhan kerohanian orang percaya berkenaan dengan ketaatannya kepada Kristus dan kesaksian kehidupannya. Sedangkan Warren (2000, p. 56) menyatakan bahwa pertumbuhan rohani berkenaan dengan kualitas kehidupan orang percaya 
yang menunjuk hidup menjadi seperti Kristus, berdiri teguh atas Firman Allah, menggunakan talentanya dalam pelayanan dan penginjilan serta bersaksi secara teratur kepada orang lain. Sama seperti Warren, Katarina dan Darmawan (2019) mengungkapkan bahwa agar orang Kristen bertumbuh secara rohani maka salah satu bagian pentingnya adalah orang Kristen dibangun di atas dasar pengenalan firman Allah. Dalam pelayanan perkunjungan, gembala menanamkan nilai-nilai alkitabiah sehingga dapat membangun rohani jemaat. Jemaat yang berkualitas dirinya akan bersaksi terhadap orang lain sebagai bentuk ketaatan dan kerinduannya untuk melayani Tuhan. Kualitas hidup rohani yang dicerminkan melalui sikap dan perbuatan yang menggambarkan dan meneladani Kristus. Sanders (2001, p. 12) menyatakan bahwa pertumbuhan rohani sebagai suatu proses yang terus menerus di dalam diri seseorang. Namun demikian, dapat dipercepat melalui ketaatannya pada Firman Tuhan. Pertumbuhan rohani ini yang tercermin dari kematangan karakter dan pengalamannya dalam Kristus (Sanders, 2001, p. 33). Pribadi yang bertumbuh dalam kehidupan rohani memiliki persekutuan dengan Allah baik melalui ibadah, maupun doa dan hidup dalam ketaatannya kepada Allah (Palau, 1990, p. 32).

Pelayanan kunjungan berpengaruh terhadap pertumbuhan rohani jemaat. Nuh, Darmawan, dan Sujoko (2019) menjelaskan bahwa dalam penelitian di GKII Tandang, salah satu bentuk pelayanan pastoral yang dilakukan untuk pertumbuhan gereja adalah perkunjungan. Hasil penelitian Susanto (2016b) juga menunjukkan bahwa pelayanan perkunjungan memiliki peran dalam pertumbuhan gereja. Panjaitan \& Siahaan (2017, p. 10) menyatakan bahwa banyak anggota yang biasanya sudah mulai malas untuk datang ke gereja, tetapi melaluikunjungan yang dilakukan gembala kerohaniannya dibangunkan kembali untuk datang memuliakan Tuhan di gereja. Dalam Matius 5:48 dinyatakan bahwa "Karena itu haruslah kamu sempurna, sama seperti Bapamu yang di sorga adalah sempurna." Kata sempurna dalam teks ini menggunakan kata dalam bahasa Yunani, yaitu

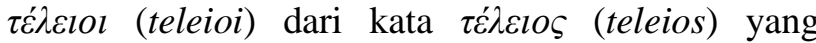
berarti lengkap, sempurna yang menunjukkan totalitas, dan menunjuk pada kedewasaan (Bibleworks, n.d.). Kesempurnaan dalam konteks ini menunjuk pada kehidupan yang meneladani Tuhan Yesus, dimana adanya progres dari pertumbuhan kehidupan rohani yang tercermin dalam setiap perkataan, tindakan dan perbuatannya. Menurut Henry (1985, p. 112) bahwa kata sempurna dalam Matius 5:48 bukanlah secara langsung melekat pada diri seseorang ketika dirinya menerima Yesus sebagai Tuhan dan Juruselamatnya. Melainkan yang harus diraih, diusahakan dan diupayakan disepanjang kehidupan. Mewujudkan kehidupan rohani yang bertumbuh diperlukan upaya dari setiap pribadi orang percaya. Gereja melalui pelayanan yang dilaksanakan gembala dengan melakukan pembinaan, pembimbingan dan menuntun jemaat untuk mengaplikasikan Firman Tuhan.Namun dari pribadi yang terkait diperlukan usaha untuk melakukan Firman Tuhan. Melalui sinergi dari kedua pihak, dimana gereja melakukan tugas dan tanggungjawabnya dengan baik, serta jemaat juga merespon dengan mengaplikasikan Firman Tuhan, maka pertumbuhan rohani akan terwujud secara optimal.

Rumusan masalah penelitian ini adalah apakah ada pengaruh pelayanan kunjungan pastoral terhadap pertumbuhan rohani jemaat? Tujuan penelitian ini adalah untuk memaparkan tentang pengaruh pelayanan kunjungan pastoral terhadap pertumbuhan rohani jemaat.

\section{METODE}

Metode penelitian yang digunakan dalam kajian ini adalah Survei - Korelasional. Penelitian survei mengkaji populasi yang besar maupun kecil, tetapi data yang dipelajari adalah data dari sampel yang diambil dari populasi, dan hasil penelitian ini dapat digeneralisasikan pada populasi. Disebut korelasional karena dalam penelitian ini mengkaji hubungan antar variabel. Dalam penelitian ini menggunakan analisis korelasional yang berfungsi untuk mengetahui derajad hubungan antara variabel-va- 
riabel (Widiyanto, 2014, p. 211). Variabel dalam penelitian ini yaitu pelayanan kunjungan pastoral dan pertumbuhan rohani. Penelitian ini dilakukan di Gereja Kemah Injil Indonesia Tenggarong tahun 2018/ 2019. Sampel penelitian ini adalah jemaat yang menerima pelayanan kunjungan pastoral sejak tahun 2016 sampai tahun 2019. Jumlah sampel penelitian ini sebanyak 60 jemaat yang diambil menggunakan teknik Stratifeid Random Sampling berdasarkan strata pendidikan. Teknik pengambilan data dilakukan dengan kuesioner terbuka dengan skala model Likert. Adapun kuesioner penelitian ini menggunakan lima alternatif pilihan jawaban. Adapun pilihan jawaban Instrumen penelitian yaitu: Sangat Sesuai (SS), Sesuai (S), Kadang-kadang Sesuai (KS), Tidak Sesuai (TS), dan Sangat Tidak Sesuai (STS). Sebelum digunakan sebagai alat pengumpul data, terlebih dahulu instrumen penelitian diuji cobakan dan dilakukan uji validitas dan reliabiltas instrumen. Pengujian validitas dilakukan dengan validitas butir (item validity) dan pengujian reliabilitas dengan menggunakan formula Alpha Cronbach. Instrumen pelayanan kunjungan pastoral terdiri dari 17 item yang valid dengan koefisien reliabilitas sebesar 0,871. Sedangkan instrumen pertumbuhan rohani terdiri dari 19 item yang valid dengan koefisien reliabilitas sebesar 0,923 . Teknik analisis data yang digunakan dengan statistika deskriptif dan statistika inferensial dengan menggunakan analisis korelasi sederhana dan regresi sederhana.

\section{HASIL}

Berdasarkan analisis deskriptif diperoleh hasil sebagai berikut:

\begin{tabular}{|l|c|c|c|c|c|}
\hline \multicolumn{1}{|c|}{ Variabel } & N & Minimum & Maximum & Mean & Std. Deviation \\
\hline Pelayanan Kunjungan Pastoral & 60 & 60 & 85 & 72.20 & 5.839 \\
\hline Pertumbuhan Rohani Jemaat & 60 & 64 & 95 & 79.65 & 7.564 \\
\hline
\end{tabular}

Sumber: Data penelitian

Tabel 1. Analisis Deskripsi Data Penelitian

Berdasarkan analisis data menunnjukkan bahwa nilai rata-rata dari variabel pelayanan kunjungan pastoral sebesar 72,20 dengan simpangan baku sebesar 5,839. Sebanyak 30 jemaat atau 50,00\% yang memiliki penilaian terhadap pelayanan kunjungan pastoral di atas rata-rata, dan sebanyak 30 orang atau $50 \%$ yang memberikan penilaian di bawah rata-rata. Hasil analisis deskriptif ini menunjukkan bahwa pelayanan pastoral dalam penilaian jemaat sudah dilaksanakan dengan cukup baik. Se- dangkan nilai rata-rata variabel pertumbuhan rohani sebesar 79,65 dengan simpangan baku sebesar 7,564 . Sebanyak 38 orang jemaat atau $63,33 \%$ yang menunjukkan kehidupan rohaninya bertumbuh di atas nilai rata-rata, dan sebanyak 22 orang atau $36,67 \%$ yang nilai pertumbuhan rohaninya di bawah nilai rata-rata. Berdasarkan hasil analisis pengujian pengaruh pelayanan kunjungan pastoral terhadap pertumbuhan rohani jemaat diperoleh sebagai berikut:

\begin{tabular}{|c|c|c|c|c|c|c|}
\hline \multicolumn{7}{|c|}{ Coefficients $^{\mathrm{a}}$} \\
\hline \multirow{2}{*}{\multicolumn{2}{|c|}{ Model }} & \multicolumn{2}{|c|}{$\begin{array}{l}\text { Unstandardized } \\
\text { Coefficients }\end{array}$} & \multirow{2}{*}{$\begin{array}{c}\text { Standardized } \\
\text { Coefficients }\end{array}$} & \multirow[b]{2}{*}{$\mathrm{T}$} & \multirow[b]{2}{*}{ Sig. } \\
\hline & & $\mathrm{B}$ & Std. Error & & & \\
\hline \multirow[t]{2}{*}{1} & (Constant) & 47.879 & 11.588 & & 4.132 & .000 \\
\hline & Pelayanan Kunjungan Pastoral & .440 & .160 & .340 & 2.751 & .008 \\
\hline
\end{tabular}

Sumber: Data penelitian

Tabel 2.Hasil Analisis Regresi dan Uji Signifikansi Persamaan Regresi 


\begin{tabular}{|c|c|c|c|c|c|c|}
\hline \multicolumn{7}{|c|}{ ANOVA $^{\mathrm{a}}$} \\
\hline \multicolumn{2}{|c|}{ Model } & $\begin{array}{l}\text { Sum of } \\
\text { Squares }\end{array}$ & Df & Mean Square & $\mathrm{F}$ & Sig. \\
\hline \multirow[t]{3}{*}{1} & Regression & 389.530 & 1 & 389.530 & 7.566 & $.008^{\mathrm{b}}$ \\
\hline & Residual & 2986.120 & 58 & 51.485 & & \\
\hline & Total & 3375.650 & 59 & & & \\
\hline
\end{tabular}

Sumber: Data penelitian

Tabel 3.Hasil Uji Signifikansi Persamaan Regresi

Dari hasil analisis pada tabel di atas diperoleh bahwa $F_{\text {hitung }}$ sebesar 7,566 dengan $P$-value sebesar 0,008. Oleh karena $P$-value lebih kecil dari 0,01 (taraf signifikansi) yang memiliki arti bahwa persamaan regresi tersebut sangat signifikan, maka persamaan regresi $\hat{Y}=47,879+0,440 X$ memiliki makna bahwa apabila skor rata-rata pelayanan kunjungan pastoral meningkat satu unit, maka skor rata-rata pertumbuhan rohani jemaat akan meningkat sebesar 0,440 pada konstanta 47,879. Sedangkan hasil analisis korelasi pengaruh pelayanan kunjungan pastoral terhadap pertumbuhan rohani jemaat menggunakan korelasi Pearson Product Moment menunjukkan bahwa:

\begin{tabular}{|l|c|c|c|c|}
\hline \multicolumn{5}{|c|}{ Model Summary } \\
\hline Model & $\mathrm{R}$ & R Square & $\begin{array}{c}\text { Adjusted R } \\
\text { Square }\end{array}$ & $\begin{array}{c}\text { Std. Error of } \\
\text { the Estimate }\end{array}$ \\
\hline 1 & $.340^{\mathrm{a}}$ & .115 & .100 & 7.175 \\
\hline a. Predictors: (Constant), Pelayanan Kunjungan Pastoral \\
\hline
\end{tabular}

Sumber: Data Penelitian

Tabel 4. Hasil Analisis Korelasi

Berdasarkan kedua tabel di atas besarnya koefisien korelasi sebesar 0,304 dan $\mathrm{t}_{\text {hitung }}$ sebesar 2,751dengan koefisien $P$-value sebesar 0,008yang lebih kecil dari 0,05; maka disimpulkan bahwa terdapat pengaruh yang signifikan pelayanan kunjungan pastoral terhadap pertumbuhan rohani jemaat. Semakin baik dalam pelaksanaan pelayanan kunjungan pastoral, maka jemaat akan samakin bertumbuh dalam kehidupan rohaninya. Besarnya koefisien determinansi $\left(\mathrm{r}_{\mathrm{yx}}^{2}\right)$ sebesar 0,115 mempunyai makna bahwa pelayanan kunjungan pastoral berperan dalam meningkatkan pertumbuhan rohani jemaat sebesar $11,5 \%$, sedangkan sisanya sebesar $88,5 \%$ dipengaruhi oleh faktor-faktor lainnya yang tidak diteliti.

\section{PEMBAHASAN}

Hasil penelitian ini menunjukkan bahwa pelayanan kunjungan pastoral berpengaruh terhadap pertumbuhan rohani jemaat. Hasil ini sejalan dengan Cedar, Hughes, \& Patterson (1991, p. 18) yang menyatakan bahwa jika gereja berhenti melakukan pelayanan kunjungan pastoral berarti menghentikan pertumbuhan gereja itu sendiri. Pertumbuhan secara secara kualitas menunjuk pada pertumbuhan dalam kehidupan rohani (Susanto, 2016a). Untuk mewujudkan gereja yang bertumbuh harus dimulai dari kehidupan rohani jemaat. Apabila kehidupan rohani bertumbuh, maka dengan sendirinya akan mengakibatkan penambahan jumlah orang percaya atau pertumbuhan gereja secara kualitas (Wongso, 2001, p. 69). Melalui pelayanan kunjungan pastoral jemaat dituntun, dibimbing dan digembalakan untuk hidup melakukan Firman Tuhan (Panggarra \& Sumule, 2019; Susanto, 2016b). Keberhasilan dalam pelayanan pastoral ditunjukkan melalui perubahan sikap hidup jemaat untuk menjadi seperti Kristus. Pertum- 
buhan rohani berdampak pada pertumbuhan gereja secara kuantitas. Pertumbuhan rohani dapat ditingkatkan melalui pelayanan kunjungan pastoral. Pelayanan kunjungan pastoral sebagai pelayanan penggembalaan yang bertujuan untuk pembinaan kehidupan rohani jemaat. Gereja tidak dapat mengabaikan pelayanan ini. Relasi yang terhambat antara gereja dengan jemaat menjadi hambatan bagi terwujudkan jemaat yang bertumbuh dalam kehidupan rohaninya. Gereja dalam konteks ini gembala jemaat memegang peranan penting untuk meningkatkan intensitas pelayanan kunjungan dalam membimbing dan menuntun jemaat bertumbuh dalam Kristus.

Ronda (2019) mengungkapkan bahwa gembala sebagai pemimpin jemaat memiliki peran penting dalam membangun rohani jemaat. Salah satu yang harus dilakukan oleh gembala menurut Ronda adalah melakukan pendekatan spiritual yang menekankan pemahaman firman Tuhan sebagai penuntun hidup di era disrupsi teknologi. Perkunjungan pastoral dapat menjadi sebuah pendekatan spiritual yang menanamkan nilai-nilai firman Tuhan sehingga akhirnya membangun pertumbuhan rohani jemaat. Demikian halnya dengan Nugroho (2017) yang mengungkapkan bahwa perkunjungan menjadi bagian dalam pelayanan pastoral yang holistik. Sementara Tafonao (2018) menjelaskan bahwa ada peran gembala untuk mengajar jemaat agar mengalami pertumbuhan rohani. Dalam tugas tersebut, perkunjungan dapat menjadi cara untuk memberikan pengajaran selain berfungsi sebagai bentuk pastoral care.

Hasil penelitian ini sejalan dengan Cowles (1977, p. 14) dan Nugroho (2017, p. 146) yang menyatakan bahwa pelayanan kunjungan sangat membantu gembala untuk mengenal jemaatnya, mengetahui kebutuhan jemaat dan dapat menyusun dan melaksanakan rencana atau tujuan pelayanannya. Tujuan pelayanan gembala untuk mewujudkan umat Tuhan yang bertumbuh dalam Kristus. Pelayanan kunjungan menjadi sarana bagi gembala dalam mengenal jemaat yang digembalakan dengan baik. Pengenalan yang baik akan membuat hubungan terjalin secara harmonis dan bersinergi bersama. Tentunya hubungan yang akrab dan penuh kasih akan menjadi kekuatan gembala dalam menuntun dan membimbing jemaat bertumbuh dalam kehidupan rohani, menjadi seperti Kristus. Selain itu, pelayanan perkunjungan dalam kaitan dengan konseling pastoral berfungsi sebagai penjangkauan yang bertujuan agar terjadi pertumbuhan rohani (Sumarto, 2019). Sebagaimana hasil penelitian yang menunjukkan bahwa ada pengaruh pelayanan perkunjungan pastoral terhadap pertumbuhan rohani jemaat, beberapa teori yang membahas tentang pelayanan perkunjungan pastoral relevan untuk terus dilaksanakan. Secara teoritis, Pelayanan perkunjungan pastoral berfungsi untuk memberikan penguatan pemahaman pada firman Tuhan sehingga mendorong terjadinya partumbuhan rohani jemaat. Jadi peran gembala jemaat sebagai pemimpin dan pembimbing umat sangat penting untuk berada di tengah-tengah umat dalam meneguhkan, membimbing dan menuntunnya mewujudkan tujuan Kristus bagi umat-Nya, yaitu menjadi pribadi yang seperti Kristus (K. Katarina \& Siswanto, 2018; Nugroho, 2017).

\section{KESIMPULAN}

Hasil penelitian diperoleh bahwa terdapat pengaruh pelayanan kunjungan pastoral terhadap pertumbuhan rohani jemaat yang ditunjukkan melalui koefisien korelasi sebesar 0,340 yang signifikan pada $\alpha=0,05$. Berdasarkan hasil analisis menunjukkan bahwa terdapat pengaruh pelayanan kunjungan pastoral terhadap pertumbuhan rohani jemaat. Semakin baik dan intens pelayanan kunjungan pastoral yang dilakukan gembala jemaat maupun Badan Pengurus Jemaat atau Majelis Gereja akan berdampak pada peningkatan pertumbuhan rohani jemaat. Pelayanan kunjungan pastoral sebagai bentuk dari pelayanan penggembalaan yang memiliki peran penting dalam membangun hubungan dengan jemaat, mengetahui kondisi jemaat yang sesungguhnya dan sebagai media dalam menuntun serta membimbing dalam menumbuhkembangkan nilai-nilai Iman Kristen. Melalui pelayanan kunjungan pastoral ini jemaat mendapatkan dukungan, dikuatkan, di- 
teguhkan dalam menghadapai realitas kehidupan serta dibimbing bertumbuh dalam kehidupan rohaninya.

Saran bagi gembala jemaat, Badan Pengurus Jemaat atau Majelis Gereja adalah tidak melalaikan pelayanan kunjungan pastoral, melainkan meningkatkannya. Seperti yang dipaparkan Kitab Yehezkiel 34 bahwa Allah murka kepada para pemimpin Israel karena mereka "sibuk menggembalakan dirinya sendiri dan menelantarkan domba-dombanya, umat Israel." Dalam Yehezkiel 34:4 jelas tertulis tegoran ini: "yang lemah tidak kamu kuatkan, yang sakit tidak kamu obati, yang luka tidak kamu balut, yang tersesat tidak kamu bawa pulang, yang hilang tidak

\section{DAFTAR RUJUKAN}

Beek, A. M. van. (1992). Konseling Pastoral: Sebuah Buku Pegangan Bagi Para Penolong di Indonesia. Satya Wacana.

Bibleworks (Version 10). (n.d.). [Computer software].

Cedar, P., Hughes, K., \& Patterson, B. (1991). Mastering The Pastoral Role. Multnomah.

Clinebell, H. J. (2006). Tipe Tipe Dasar Pendampingan dan Konseling Pastoral. Kanisius.

Cowles, R. (1977). Gembala Sidang. Kalam Hidup.

Henry, M. (1985). Matthew Henry's commentary on the whole Bible: Matthew To John. MacDonald.

Ingouf, J. E. (1988). Sekelumit Tentang Gembala Sidang. Lembaga Literatur Baptis.

Katarina, K., \& Darmawan, I. P. A. (2019). Implikasi Alkitab dalam Formasi Rohani pada Era Reformasi Gereja. EPIGRAPHE: Jurnal Teologi Dan Pelayanan Kristiani, $3(2)$, 81-93. https://doi.org/10.33991/epigraphe.v3i2.85

Katarina, K., \& Siswanto, K. (2018). Keteladanan Kepemimpinan Yesus Dan Implikasinya Bagi Kepemimpinan Gereja Pada Masa Kini. Evangelikal: Jurnal Teologi Injili dan Pembinaan Warga Jemaat, 2(2), 87-98. kamu cari." Jadi gembala jemaat berperan untuk memimpin dan membimbing umat, kemudian berada di tengah-tengah umat dalam meneguhkan, membimbing dan menuntunnya menjadi pribadi yang seperti Kristus. Hendaknya pelayanan kunjungan pastoral tidak hanya dilakukan ketika jemaat mengalami sakit atau musibah, melainkan dilakukan penjadwalannya secara rutin serta menjadi program prioritas gereja. Hendaknya dilakukan penelitian lebih lanjut pada aspek-aspek yang mempengaruhi pertumbuhan rohani jemaat, dilihat dari aspek penggembalaan lainnya seperti konseling pastoral dan sebagainya.

Kosta, Y., \& Djadi, J. (2011). Peranan Gembala Sebagai Pemimpin Dalam Perspektif I Petrus 5:1-4 Dan Relevansinya Pada Masa Kini. Jurnal Jaffray, 9(2), 172-200. https://doi.org/10.25278/jj71.v9i2.100

Mimery, N. (1996). Rahasia Tentang Penggembalaan Jemaat. Mimery Press.

Nugroho, F. J. (2017). Pendampingan Pastoral Holistik: Sebuah Usulan Konseptual Pembinaan Warga Gereja. Evangelikal: Jurnal Teologi Injili dan Pembinaan Warga Jemaat, 1(2), 139-154.

Nuh, S., Darmawan, I. P. A., \& Sujoko, E. (2019). Implementasi PAK Konteks Gereja Di GKII Tandang, Semarang. Pengarah: Jurnal Teologi Kristen, 1(1), 59-70. https://doi.org/10.36270/pengarah.v1i1.7

Palau, L. (1990). Bertumbuh Secara Rohani. BPK Gunung Mulia.

Panggarra, R., \& Sumule, L. (2019). Pengaruh Pelayanan Pemuda Berbasis Kontekstual Terhadap Pertumbuhan Gereja Kemah Injil Indonesia di Kota Samarinda. Jurnal Jaffray, $\quad$ 17(1), 91-106. https://doi.org/10.25278/jj71.v17i1.325

Panjaitan, J., \& Siahaan, M. (2017). Analisis Persepsi Anggota Jemaat Wilayah 13 
tentang Pengaruh Pelawatan Gembala terhadap Keterlibatan Jemaat dalam Pelayanan Di Gereja Masehi Advent Hari Ketujuh Berdasarkan Mazmur 23:1-4. Jurnal Marturia, 1(1), 1-24.

Pranoto, F., Eliawaty, I., \& Permana, S. (2018). Pelayanan Pastoral Dengan AspekAspeknya di Gereja Bethel Indonesia Jemaat Sungai Yordan Surabaya. Journal KERUSSO, 3(2), 25-29. https://doi.org/10.33856/kerusso.v3i2.95

Riemer, G. (2005). Jemaat Yang Pastoral: Kunjungan Rumah-Pacu Jantung Pertumbuhan Gereja. Yayasan Komunikasi Bina Kasih/OMF.

Ronda, D. (2019). Kepemimpinan Kristen Di Era Disrupsi Teknologi. Evangelikal: Jurnal Teologi Injili dan Pembinaan Warga Jemaat, 3(1), 1-8.

Sanders, O. (2001). Tinggalkan Sifat Kekanakkanakan. Gandum Mas.

Sumarto, Y. (2019). Konseling Dan Pertumbuhan Gereja. CURA ANIMARUM, 1(1), 80-95.
Susanto, S. (2016a). Kemandirian Jemaat. Sekolah Tinggi Teologi Simpson.

Susanto, S. (2016b). Strategi Pembinaan Warga Jemaat Dalam Meningkatkan Kehidupan Jemaat (Studi Kasus di GKII Tandang). Prosiding Seminar Nasional Pendidikan Agama Kristen dan call for papers. Seminar Nasional Pendidikan Agama Kristen \& call for papers, Ungaran. http://semnas.sttsimpson.ac.id/index.php/SN $\mathrm{PK} /$ article/view/2

Tafonao, T. (2018). Peran Gembala Sidang Dalam Mengajar Dan Memotivasi Untuk Melayani Terhadap Pertumbuhan Rohani Pemuda. Evangelikal: Jurnal Teologi Injili dan Pembinaan Warga Jemaat, 2(1), 36-49.

Warren, R. (2000). Pertumbuhan Gereja Masa Kini, Gereja Yang Digerakkan Oleh Tujuan. Gandum Mas.

Widiyanto, M. A. (2014). Statistika untuk Penelitian Bidang Teologi, Pendidikan Agama Kristen, dan Pelayanan Gereja. Kalam Hidup.

Wongso, P. (2001). Tugas Gereja Dan Misi Masa Kini. Seminari Alkitab Asia Tenggara. 